\title{
Deep Inspiration Breath Hold: Techniques and Advantages for Cardiac Sparing During Breast Cancer Irradiation
}

\author{
Carmen Bergom ${ }^{1 *}$, Adam Currey ${ }^{1}$, Nina Desai ${ }^{1}$, An Tai ${ }^{1}$ and Jonathan B. Strauss ${ }^{2}$ \\ 'Department of Radiation Oncology, Medical College of Wisconsin, Milwaukee, WI, United States, ${ }^{2}$ Department of Radiation \\ Oncology, Feinberg School of Medicine, Northwestern University, Chicago, IL, United States
}

OPEN ACCESS

Edited by:

Minesh P. Mehta, Baptist Health South Florida, United States

Reviewed by: Shahed Nicolas Badiyan, University of Maryland Medical Center, United States Vivek Verma, University of Nebraska Medical Center, United States

*Correspondence: Carmen Bergom cbergom@mcw.edu

Specialty section: This article was submitted to Radiation Oncology, a section of the journal

Frontiers in Oncology

Received: 03 January 2018 Accepted: 13 March 2018 Published: 04 April 2018

Citation: Bergom C, Currey A, Desai N, Tai A and Strauss JB (2018) Deep Inspiration Breath Hold: Techniques and Advantages for Cardiac Sparing During Breast Cancer Irradiation. Front. Oncol. 8:87. doi: 10.3389/fonc.2018.00087
Historically, heart dose from left-sided breast radiotherapy has been associated with a risk of cardiac injury. Data suggests that there is not a threshold for the deleterious effects from radiation on the heart. Over the past several years, advances in radiation delivery techniques have reduced cardiac morbidity due to treatment. Deep inspiration breath hold $(\mathrm{DIBH})$ is a technique that takes advantage of a more favorable position of the heart during inspiration to minimize heart doses over a course of radiation therapy. In the accompanying review article, we outline several methods used to deliver treatment with $\mathrm{DIBH}$, quantify the benefits of $\mathrm{DIBH}$ treatment, discuss considerations for patient selection, and identify challenges associated with DIBH techniques.

Keywords: deep inspiration breath hold, breast cancer, radiation, active breathing control, real-time position management, heart, cardiac irradiation

\section{INTRODUCTION AND BACKGROUND}

Although it is well known that radiation therapy for breast cancer has both local control and survival benefits $(1,2)$, many have questioned whether the associated toxicities and resulting mortality may actually negate some of the survival benefit $(3,4)$. It has been hypothesized that this mortality is specifically related to cardiac mortality, and studies have demonstrated that patients who receive radiation therapy for left-sided breast cancers have increased cardiac mortality $(5,6)$. In fact, mean radiation dose to the heart correlates with rates of both cardiac deaths $(7,8)$ and coronary events $(8$, 9). While the risk of cardiac toxicity is also influenced by other factors, such as the patient's baseline cardiac risk, as well as cardiotoxic chemotherapy (10-12), these effects may not be synergistic (9). The risk of heart disease and coronary events is estimated to increase 4-7\% for each 1 Gy in mean heart dose, and there does not appear to be a minimum dose threshold below which there is no risk of cardiac events $(9,13)$. Additionally, while irradiation of internal mammary chain (IMC) lymph nodes is still controversial $(14,15)$, more recent studies highlight the potential benefits of regional nodal irradiation $(16,17)$, which may increase the incidence of nodal irradiation in the future. As IMC irradiation is known to increase the heart dose when compared to whole breast or chest wall (CW) alone treatment (18), reducing cardiac dose and associated toxicity from radiation therapy may become even more important.

The studies which remain the basis for cardiac toxicity from radiation are from the pre-threedimensional (3D) conformal radiation therapy era $(4,5,19,20)$, and advances in radiation therapy since then have decreased the mean heart dose $(4,6,19,21)$. Some of the techniques which have been shown to decrease heart dose include both prone breast radiation therapy, where the patient 
is simulated and treated, lying on the abdomen to pull the breast away from the heart (22), as well as proton therapy $(23,24)$. Of note, while modern techniques such as intensity-modulated radiation therapy (IMRT) decrease the volume of heart that receives high doses, a larger volume may receive lower doses, due to low-dose spray associated with the technique (25).

Another technique that can be used to decrease heart dose is deep inspiration breath hold (DIBH). The technique is based upon the observation that during inspiration, the flattening of the diaphragm and expansion of the lungs pulls the heart away from the CW. During both simulation and treatment, the patient takes a deep breath and then holds it for a period of time during which radiation is administered. This allows for a decrease in radiation dose to the heart (Figures 1A,B) (26). While DIBH can be used alternatively to prone breast irradiation (27), the two techniques can and have been used in conjunction $(28,29)$.

\section{DIBH METHODS}

Currently, there are two very commonly used techniques for $\mathrm{DIBH}$, voluntary DIBH (vDIBH), and moderate DIBH. Moderate $\mathrm{DIBH}$ is a technique whereby devices known as active breathing control (ABC) devices are used (30) (e.g., ABC from Elekta, Stockholm, Sweden). These devices typically utilize a spirometer which allows for monitoring of air flow throughout the respiratory cycle and stopping air flow at a set threshold volume, causing the patient to hold their breath to maintain this volume (30-32). This has not only been shown to decrease the heart and left anterior descending artery (LAD) dose (Table 1), but has also proven to be very reproducible, which is always a concern when using motion management for radiotherapy. Specifically, one study demonstrated that $\mathrm{ABC}$ devices could reduce the set-up error to less than $2 \mathrm{~mm}$, and in some cases, even $1 \mathrm{~mm}$. Hence, a potential benefit of the $\mathrm{ABC}$ device is its ability to decrease the variability associated with the procedure, both within a fraction and between separate fractions.

Alternatively, patients can undergo vDIBH, where respiratory motion is monitored, and the patient is instructed to hold his or her breath at certain points in the breathing cycle. One example of this technique is the Varian RPM (real-time position management) system (Varian Medical Systems, Palo Alto, CA, USA), where a device is placed on the patient's chest and vertical displacement throughout the respiratory cycle provides surrogate data to create a tracing of the patient's breathing (Figures 1C,D). With this technique, the patient is coached and must voluntarily hold their breath. The treatment beam can be gated so that treatment is stopped when the breathing signal falls outside a preset threshold. This type of gating in DIBH, in which the beam is turned off only in the event that the breath hold is out of target range, should be differentiated from standard respiratory gating, in which the patient is breathing free and the beam is repeatedly turned off during a predetermined portion of the respiratory cycle. Unlike DIBH, respiratory gating at free breathing is not usually an effective method for cardiac sparing because at no point in the standard respiratory cycle does the heart move dramatically away from the breast or chest wall. It appears that vDIBH is quite comparable to ABC DIBH on multiple levels. The
UK HeartSpare study (61) compared the two techniques using a crossover study, where patients initially received treatment with one DIBH technique for one half, followed by the other technique for the other half of their therapy. The study noted similar overall treatment times, but found that vDIBH was associated with decreased time for both simulation and daily setup. Additionally, both patients and therapists endorsed greater satisfaction with the vDIBH technique (61). In fact, a study by Eldredge-Hindy et al. noted that $18 \%$ of the 112 patients enrolled in their study did not tolerate the ABC technique (62). All of these studies, along with the fact that vDIBH can be executed relatively cheaply $(61,63)$, question whether $\mathrm{ABC}$ is necessary for DIBH.

Optical tracking systems are more advanced tools (e.g., AlignRT, Vision RT Ltd., London, UK; Sentinel, C-RAD, Uppsala, Sweden) for DIBH (64), because RPM was shown to have inferior correlation with the target position, determined via MV cine imaging (65). In optical tracking systems, stereovision is used to reconstruct the $3 \mathrm{D}$ surface of the patient, visualizing the alignment of the reference surface and the reconstructed surface at the region of interest to provide real-time position monitoring (Figures 1E,F) (65-67). Betgen et al. (68) performed vDIBH using an optical surface tracking system. After set-up corrections, variations in chest excursion for each breathhold within a treatment fraction and within a treatment field were found to be very small, demonstrating reliable geometry of the CW (68) during a DIBH treatment. Another study also demonstrated high patient setup accuracy with the use of optical surface imaging (69). Similarly, when magnetic sensors were affixed to the thorax to measure chest excursion during DIBH, the SD of the amplitude of chest motion for each patient was $<3 \mathrm{~mm}$, indicating that the magnitude of inspiration could be reliably reproduced (70). Additionally, other manual checkpoints during the treatment, such as positioning of tattoo markings $(61,71)$ and image guidance (35) both ensure proper setup. More typically, a combination of the above-mentioned techniques is utilized (63).

For DIBH treatment, at least two CT scans corresponding to free breathing and DIBH have to be acquired during simulation. Patients are coached to breathe through their nose instead of mouth. The patient contours on the two CT scans will be used to match the corresponding daily patient surfaces from the optical tracking system during treatment setup for assuring that patients reach the same level of breathhold as that during simulation. When treating the left-sided breast patients with nodal involvement using DIBH delivery, both nodal and breast fields should be delivered at breathhold due to the matchline between nodal and breast fields. Feathering of the matchline may not be necessary during treatment because a $3 \mathrm{~mm}$ threshold of DIBH position uncertainty is usually applied in the surface tracking systems. The number of field-in-fields should be minimized (preferably $<4$ fields) for more rapid treatment delivery. This is one reason why IMRT planning is not often combined with DIBH delivery. Some types of bolus may not be tracked well by the optical tracking system. Wet towels may be used to replace the more rigid bolus during DIBH delivery (72). Alternatively, a conformal brass bolus can be used and cloth tape can be placed over the bolus to increase contrast for the optical tracking system. 
A

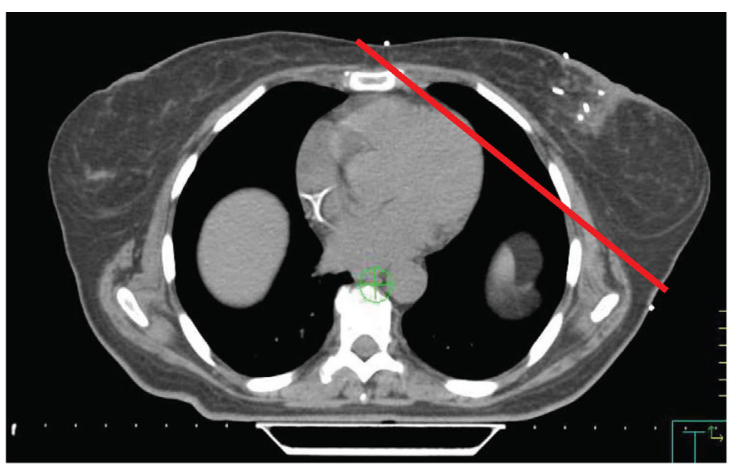

C

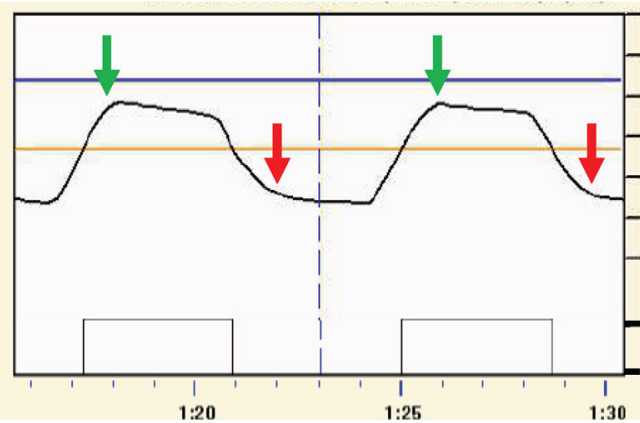

E

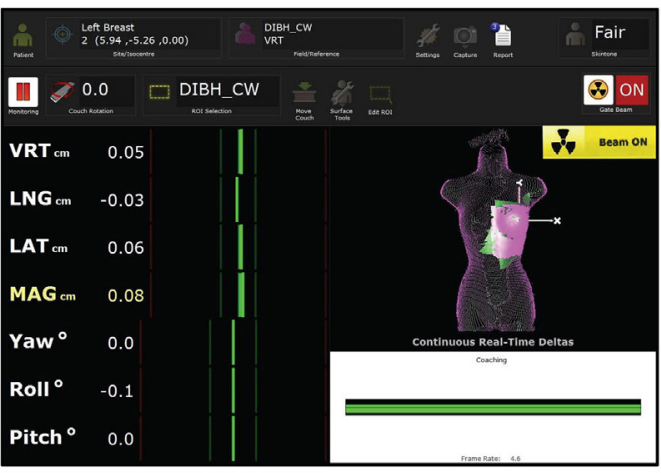

G

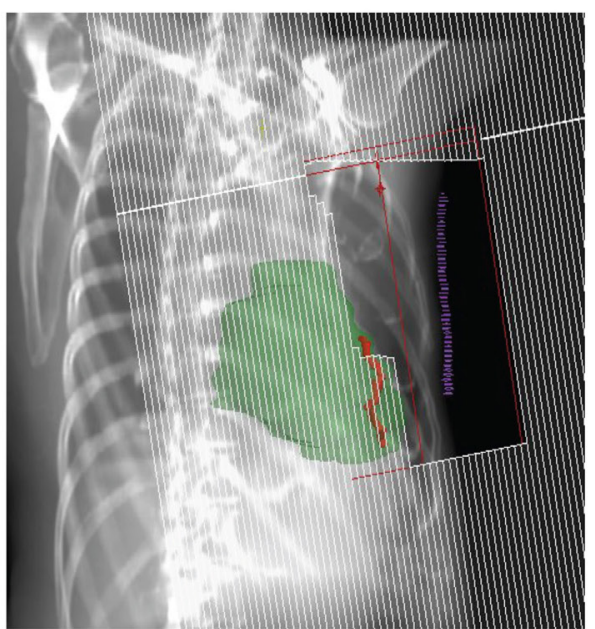

$B$

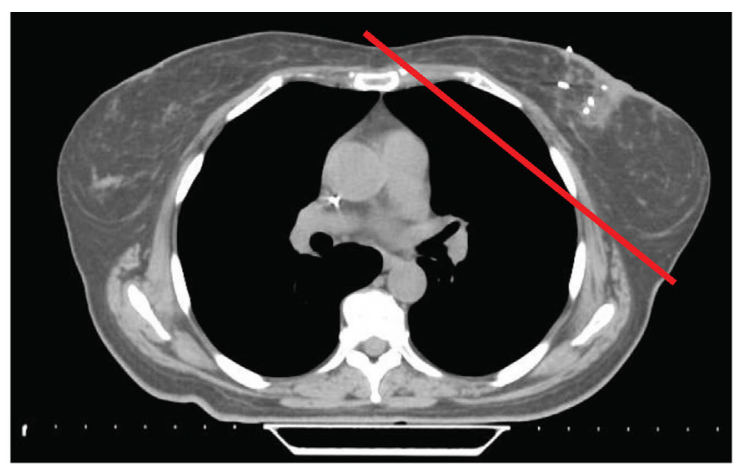

D

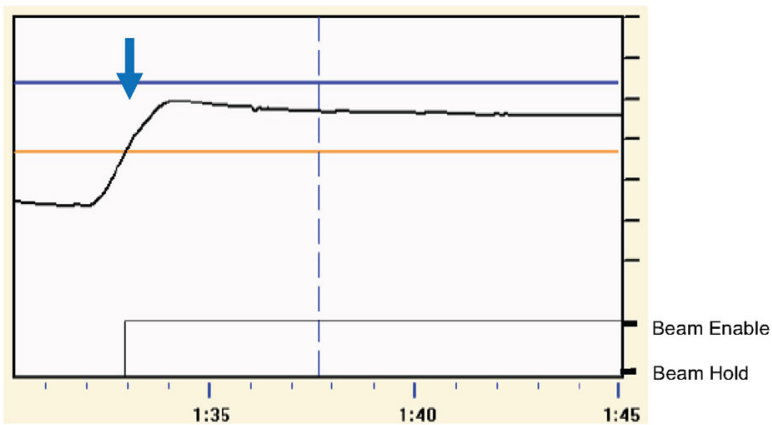

$\mathbf{F}$

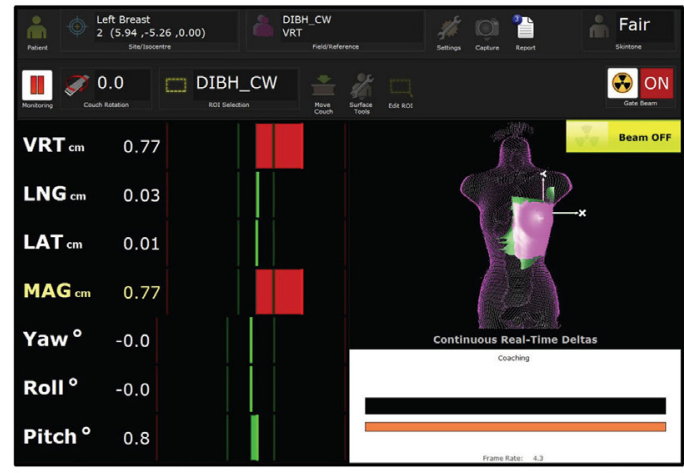

H

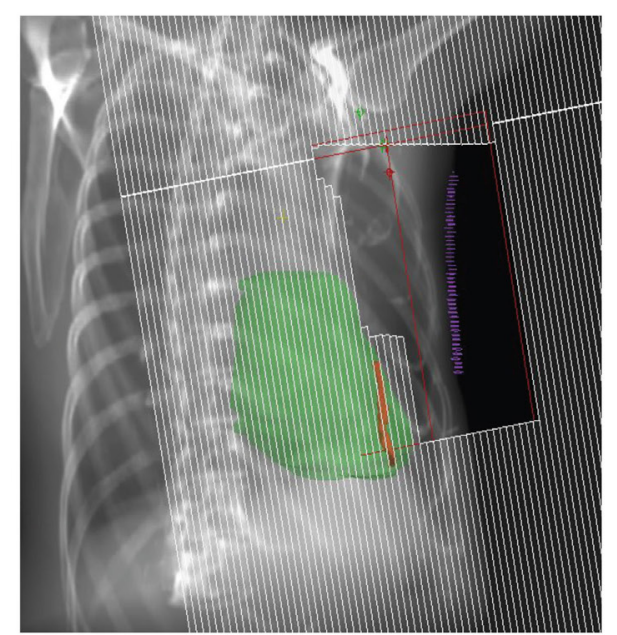

FIGURE 1 | Continued 


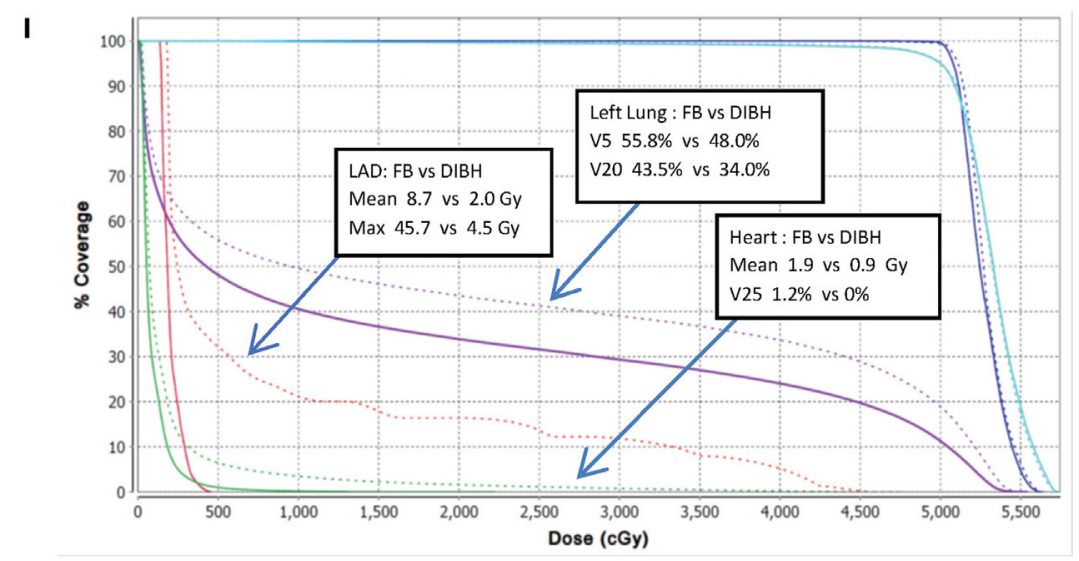

FIGURE 1 | Deep inspiration breath hold (DIBH) techniques and examples of anatomic and dosimetric advantages. (A,B) Axial CT slices from the same level of the breast in free breathing (A) and $\mathrm{DIBH}(\mathbf{B})$ CT scans. The red line indicates the tangential radiation field used for whole breast radiation treatment. Note that the heart is easily excluded in the DIBH scan. (C,D) DIBH respiratory tracings and real-time patient monitoring (RPM) using optical tracking at inspiration (green arrow) and expiration (red arrow) during free breathing. (D) RPM tracings confirm appropriate chest excursion during DIBH, with a stable breath hold tracing. After inspiration (blue arrow) with $\mathrm{DIBH}$, the beam would be on during the sustained breath hold. (E) AlignRT screenshot illustrates a reference surface on the chest wall (CW) used for alignment with a region of interest (left breast), which is matched during surface tracking, and with DIBH, when the left breast is within the preset thresholds, as indicated by the dynamic green bars on the side of the panel, the treatment beam is enabled. (F) With expiration or any movements of the left breast outside of tolerance, the green bars turn red and the radiation beam is held. This process continues until the whole radiation dose is delivered daily. (G,H) Digitally reconstructed radiographs from a patient in during free breathing $\mathbf{( G )}$ and voluntary $\mathrm{DIBH}(\mathrm{vDIBH}) \mathbf{( H )}$ demonstrating the favorable shift in heart (green) and left anterior descending artery (LAD) (red) positions in relation to CW tangent with vDIBH. (I) The dose volume histogram comparison of free breathing and vDIBH three-dimensional conformal radiation therapy plans for patient in $\mathbf{( G , H )}$ treating the left $\mathrm{CW}$ to 50 plus a 10 Gy boost, and regional lymph nodes including the supraclavicular and internal mammary chain nodes to 50 Gy. The organs are at risk in the vDIBH plan (solid lines), including the heart (green lines), left (Lt) lung (purple lines), and LAD (red lines), receive decreased doses when compared to the free breathing plan (dotted lines). The mean, max, and/or volumetric doses for these organs are provided in the boxes.

\section{ADVANTAGES OF DIBH AND PATIENT SELECTION}

As cardiac toxicity due to radiation therapy has a prolonged latency period, no clinical data exists on the effects of DIBH on cardiac morbidity and mortality, and it is currently too soon to tell if it effectively improves these outcomes. Despite this, many dedicated dosimetric comparisons have noted the benefits of $\mathrm{DIBH}$, especially with regards to heart dose parameters. DIBH has been associated with significant improvements in both mean heart doses and mean LAD doses, with respective decreases of 25-67 and 20-73\% when comparing the same patients planned with free breathing and DIBH (Table 1). Additionally, real world retrospective data from a large analysis of both community and academic centers also demonstrates that patients treated with DIBH had on average lower heart doses than those treated with free breathing (73).

Studies have noted perfusion defects in those patients who underwent radiation therapy for left-sided breast cancers, with defects correlating to the radiation fields used for treatment $(74,75)$. Moreover, no perfusion defects were found in patients treated with radiation fields that excluded the heart entirely (76, 77). While a study by Zellars et al. did not find a difference in the incidence of perfusion defects when comparing $A B C$ with free breathing, excluding the heart completely from the treatment field was not required in this study (78). Despite differences in outcomes, the combined data may suggest that DIBH can potentially reduce cardiac toxicity from radiation therapy. It appears that the benefit of DIBH for heart dose spans across 3D and IMRT treatments and those patients undergoing nodal and/or CW irradiation (79). An example of heart movement with respect to chest wall tangent position with free breathing and vDIBH, along with accompanying dose volume histogram (DVH) comparing mean heart and LAD doses for both a standard free breathing and $\mathrm{vDIBH}$ plan for a patient receiving $\mathrm{CW}$ and regional nodal irradiation is shown in Figures 1G-I.

Although DIBH is well tolerated by most patients, patients should be screened and carefully selected after taking into account factors such as ability to tolerate the technique, cost, patient convenience, and potential benefit based on size, location, and type of tumor. As noted previously, patients with left-sided breast cancers appear to have increased cardiac mortality simply due to the proximity of the target to the heart, therefore, it is likely these patients that would benefit most from the DIBH technique. Based on this, many centers currently only offer DIBH to patients with left-sided disease.

Patients with right-sided breast cancers may also benefit from $\mathrm{DIBH}$, largely due to decreased ipsilateral and total lung doses associated with use of DIBH in patients receiving IMC radiation (60). Additionally, DIBH has been shown to more significantly decrease the heart dose in women receiving nodal irradiation to the IMC (56), largely due to the increased heart dose associated with IMC treatment when compared to treatment of the breast and CW alone (18). While the cardiac toxicity associated with IMC irradiation is worse with left-sided disease, the risk applies to patients with both left- and right-sided disease due 
TABLE 1 | Reduction of mean LAD and heart doses in studies examining free breathing versus DIBH techniques for breast cancer radiation treatment.

\begin{tabular}{|c|c|c|c|c|c|c|c|c|c|}
\hline \multirow[t]{2}{*}{ Study } & \multirow[t]{2}{*}{ DIBH method } & \multirow{2}{*}{$\begin{array}{c}\text { \# } \\
\text { Patients }\end{array}$} & \multirow[t]{2}{*}{ Area(s) treated } & \multicolumn{3}{|c|}{ Mean LAD dose (Gy) } & \multicolumn{3}{|c|}{ Mean heart dose (Gy) } \\
\hline & & & & FB & DIBH & Reduction & FB & DIBH & Reduction \\
\hline Stranzl and Zurl (33) & $\begin{array}{l}\text { voluntary DIBH } \\
(\mathrm{vDIBH})(\mathrm{RPM})\end{array}$ & 22 & Breast $/ C W \pm$ boost & - & - & - & 2.3 & 1.3 & $44 \%$ \\
\hline Stranzl et al. (34) & vDIBH (RPM) & 11 & Breast/CW + IMC LN & - & - & - & 4.0 & 2.5 & $38 \%$ \\
\hline Borst et al. (35) & vDIBH (other) & 19 & Breast/CW \pm boost & 11.4 & 5.5 & $52 \%$ & 5.1 & 1.7 & $67 \%$ \\
\hline Johansen et al. (36) & vDIBH (RPM) & 16 & Breast & - & - & - & 6.5 & 2.5 & $62 \%$ \\
\hline Mclntosh et al. (37) & vDIBH (RPM) & 10 & Breast & $\begin{array}{l}\text { Not } \\
\text { reported }\end{array}$ & $\begin{array}{l}\text { Not } \\
\text { reported }\end{array}$ & $43 \%$ & $\begin{array}{l}\text { Not } \\
\text { reported }\end{array}$ & $\begin{array}{l}\text { Not } \\
\text { reported }\end{array}$ & $48 \%$ \\
\hline Vikstrom et al. (38) & vDIBH (RPM) & 17 & Breast & 18.1 & 6.4 & $65 \%$ & 3.7 & 1.7 & $54 \%$ \\
\hline Hayden et al. (39) & vDIBH (RPM) & 30 & Breast + boost & 33.7 & 21.9 & $35 \%{ }^{\mathrm{e}}$ & 6.9 & 4.0 & $42 \%$ \\
\hline Hjelstuen et al. (40) & vDIBH (RPM) & 17 & Breast $+\mathrm{SCV}+\mathrm{Ax}+\mathrm{IMC} L N$ & 25.0 & 10.9 & $56 \%$ & 6.2 & 3.1 & $50 \%$ \\
\hline Wang et al. (41) & $\mathrm{ABC}$ & 20 & Breast & 20.0 & 5.9 & $71 \%$ & 3.2 & 1.3 & $59 \%$ \\
\hline Bruzzaniti et al. (42) & vDIBH (RPM) & 8 & Breast & 9.0 & 2.7 & $70 \%$ & 1.7 & 1.2 & $29 \%$ \\
\hline Lee et al. (43) & vDIBH (RPM) & 25 & Breast & 26.3 & 16.0 & $39 \%$ & 4.5 & 2.5 & $44 \%$ \\
\hline Mast et al. (44) & $\mathrm{ABC}$ & 20 & Breast & $\begin{array}{l}18.6 \\
14.9\end{array}$ & $\begin{array}{l}9.6 \\
6.7\end{array}$ & $\begin{array}{l}48 \%^{a} \\
55 \%^{b}\end{array}$ & $\begin{array}{l}3.3 \\
2.7\end{array}$ & $\begin{array}{l}1.8 \\
1.5\end{array}$ & $\begin{array}{l}45 \%^{a} \\
44 \%^{b}\end{array}$ \\
\hline Nissen and Appelt (45) & $\mathrm{ABC}$ & $227^{c}$ & Breast/CW $\pm S C V+A x L N$ & - & - & - & 5.2 & 2.7 & $48 \%$ \\
\hline Reardon et al. (46) & vDIBH (RPM) & 10 & Breast & 2.5 & 1.8 & $29 \%$ & 1.6 & 0.9 & $45 \%{ }^{f}$ \\
\hline Swanson et al. (47) & $\mathrm{ABC}$ & 87 & Breast/CW $\pm S C V+A x L N$ & - & - & - & 4.2 & 2.5 & $40 \%$ \\
\hline Bolukbasi et al. (48) & vDIBH (RPM) & $\begin{array}{l}10 \\
10\end{array}$ & Breast & $\begin{array}{l}1.7 \\
5.0\end{array}$ & $\begin{array}{l}0.8 \\
4.0\end{array}$ & $\begin{array}{l}53 \%^{g} \\
20 \%^{n}\end{array}$ & $\begin{array}{l}1.7 \\
4.9\end{array}$ & $\begin{array}{l}0.7 \\
3.7\end{array}$ & $\begin{array}{l}59 \%^{g} \\
25 \%^{n}\end{array}$ \\
\hline Comsa et al. (49) & $\mathrm{ABC}$ & $\begin{array}{l}20 \\
30\end{array}$ & $\begin{array}{l}\text { Breast } \pm \text { boost } \\
\text { Breast/CW + SCV + Ax LN }\end{array}$ & - & - & - & $\begin{array}{l}3.1 \\
4.5\end{array}$ & $\begin{array}{l}1.2 \\
2.1\end{array}$ & $\begin{array}{l}61 \% \\
53 \%\end{array}$ \\
\hline Osman et al. (50) & vDIBH (RPM) & 13 & Breast $+\mathrm{SCV}+\mathrm{Ax}+\mathrm{IMC} L N$ & - & - & - & $\begin{array}{l}9.0 \\
5.8\end{array}$ & $\begin{array}{l}5.0 \\
4.1\end{array}$ & $\begin{array}{l}44 \%^{a} \\
29 \%^{b}\end{array}$ \\
\hline Verhoeven et al. (27) & vDIBH (RPM) & 17 & Breast & 30.9 & 22.4 & $28 \%$ & 3.5 & 1.6 & $54 \%$ \\
\hline Eldredge-Hindy et al. (51) & $\mathrm{ABC}$ & 86 & $\begin{array}{l}\text { Breast } \pm \text { boost } \pm S C V+A x \pm I M C \\
L N\end{array}$ & - & - & - & 2.7 & 0.9 & $67 \%^{d}$ \\
\hline Joo et al. (52) & vDIBH (RPM) & 32 & Breast/CW $\pm S C V+A x$ & 40.8 & 23.7 & $42 \%$ & 7.2 & 2.8 & $61 \%$ \\
\hline Mulliez et al. (28) & vDIBH (RPM) & 12 & Breast & 17.6 & 10.9 & $38 \%$ & 4.0 & 2.2 & $45 \%$ \\
\hline Rochet et al. (53) & vDIBH (other) & 35 & Breast/CW $\pm S C V+A x+I M C L N$ & 14.9 & 4.0 & $73 \%$ & 2.5 & 0.9 & $64 \%$ \\
\hline Tanguturi et al. (54) & vDIBH (AlignRT) & 146 & Breast/CW $\pm S C V+A x \pm I M C L N$ & - & - & - & 2.6 & 1.4 & $46 \%$ \\
\hline Wiant et al. (55) & vDIBH (other) & 25 & Breast & - & - & - & 3.0 & 1.4 & $53 \%$ \\
\hline Yeung et al. (56) & vDIBH (other) & 20 & Breast/CW $\pm S C V+A x+I M C L N$ & 13.6 & 4.1 & $70 \%$ & 2.6 & 1.3 & $50 \%$ \\
\hline Walston et al. (57) & vDIBH (AlignRT) & $\begin{array}{l}7 \\
8\end{array}$ & $\begin{array}{l}\text { Breast } \pm \text { boost } \\
\text { CW } \pm \text { boost } \pm \text { SCV }+A x+I M C L N\end{array}$ & - & - & - & $\begin{array}{l}1.3 \\
5.1\end{array}$ & $\begin{array}{l}0.9 \\
3.6\end{array}$ & $\begin{array}{l}31 \% \\
29 \%\end{array}$ \\
\hline Lawler and Leech (58) & RPM & 28 & Breast/CW $\pm \mathrm{SCV}$ & 10.9 & 5.2 & $52 \%$ & 1.8 & 1.2 & $33 \%$ \\
\hline Kunheri et al. (59) & $\mathrm{ABC}$ & 45 & Breast & 13.2 & 6.1 & $54 \%$ & 3.1 & 1.6 & $52 \%$ \\
\hline Mohamad et al. (60) & $\mathrm{ABC}$ & 22 & Breast/CW + SCV + Ax + IMC LN & 21.3 & 9.4 & $56 \%$ & 5.8 & 2.2 & $62 \%$ \\
\hline
\end{tabular}

$A B C$, active breathing coordinator; $A x$, axillary; CW, chest wall; DIBH, deep inspiration breath hold; Gy (gray); FB, free breathing; IMC, internal mammary chain; LAD, left anterior descending coronary artery; LN, Iymph nodes; RPM, real-time positioning management system; SCV, supraclavicular; IMRT, Intensity modulated radiation therapy.

a $3 D$ conformal radiation therapy.

'DMRTNMAT.

¿227 left-sided (144 received DIBH; 83 received FB treatment).

${ }^{\prime}$ Median values for mean doses.

e $L A D$ planning organ at risk volume (PRV).

${ }^{t} F B-I M R T$ versus $3 D-D I B H$.

gFB versus DIBH forward-planned IMRT.

${ }^{h} F B$ versus DIBH inverse-planned IMRT.

to proximity of the target to the heart. DIBH use in right-sided patients can also result in lowered ipsilateral lung and liver doses (80). Hence, these patients with right-sided disease and concern for lung dose, as well as patients undergoing IMC irradiation should also be considered for DIBH. Tolerability of the technique, as noted above, should also be a consideration. While the technique is well tolerated overall, DIBH treatment can take longer when compared to a standard free breathing technique, 
and patients should be able to lie comfortably flat on their back for the duration of treatment.

One also questions whether patient-specific factors such as anatomical variations should play into patient selection for DIBH. Maximum heart distance, which is defined as the maximum distance within the radiation field between the anterior edge of the heart contour and the posterior border of the tangent field, has been shown to correlate with the mean heart dose $(81,82)$. A study by Rochet et al. also found that the parasagittal cardiac contact distance, as measured in free breathing, can be used to predict heart dose, with longer distances correlating with higher doses (53). Lee et al. noted similar findings with heart contact both in the axial and parasagittal planes being strongly correlated with mean heart dose (83). These studies suggest that patients with these anatomic factors may benefit most from DIBH. Therefore, consideration should be made to measure these distances on the free-breathing scan and use them as predictive factors for patients who should be selected for DIBH. Within patients who undergo $\mathrm{DIBH}$, patients who have the greatest change in lung volumes between DIBH and free-breathing scans tend to derive the greatest benefit from DIBH in terms of heart dose (54). Despite this, at least $75 \%$ of patients who undergo DIBH appear to derive benefit due to decreased heart dose (53). Other anatomic factors can also influence cardiac doses. A more pendulous left breast could lower the inferior border of the tangential fields and, therefore, increase the heart dose. In addition, a tumor bed situated more posterior may cause the dose from the boost fields to impact heart doses. A rapid planning method to generate a free-breathing plan in 9 min was introduced by Wang et al. (41) to help with DIBH patient selection. If the free-breathing plan resulted in a heart V50\% greater than $10 \mathrm{~cm}^{3}$, the patient was considered to have unfavorable cardiac anatomy and DIBH planning was recommended.

Treatment planning for DIBH plans is not unlike planning for free-breathing breast plans. Much like free breathing, treatment modalities include $3 \mathrm{D}$ radiation therapy, IMRT, as well as arc therapy $(34,48,50)$. Some studies have reported that wide tangents, when combined with $\mathrm{DIBH}$, may reduce cardiac dose even further (34), and the technique has been favored by many with regard to treatment of the IMCs $(84,85)$. In addition, the wide tangent technique achieved superior IMC dose coverage compared to the traditional photon-electron technique $(86,87)$, which makes wide tangents the favorable technique in $\mathrm{DIBH}$ planning for IMC irradiation. However, a recent paper from Borm et al. evaluated the dosimetric impact of DIBH on the axillary lymph nodes (88). In this study, the authors demonstrated that the axillary nodes move with DIBH, and the magnitude of that movement is significantly different than the movement of the lumpectomy cavity and the breast. This can result in a reduction of incidental dose to the axilla, with the mean dose to the level 1 axilla reduced by roughly $10 \%$ (88). For patients with a positive sentinel node biopsy who forgo axillary dissection, this incidental radiation dose to axillary level 1 may contribute to the low risk of axillary recurrence risk observed in patients treated in this manner $(89,90)$. Consequently, if therapeutic dose to the level 1 axilla is desired, these authors recommend delineating that region as a target and designing fields appropriately to cover the target.
Another consideration with DIBH is variability in organ and structure position both within and between treatments. The breast itself has been found to have both inter- and intrafractional reproducibility during DIBH treatments $(68,91)$, with minimal shifts when aligning to bony anatomy (37). Reassuringly, the interfraction positional variability of the LAD is comparable between DIBH and free breathing (92), while the LAD displacement at DIBH has been noted to be more variable (93). The LAD displacement could result in different cardiac doses than predicted with planning, with significant increases in heart dose when a field sets up too "deep," but small decreases in heart dose when a field is too "shallow." The results may be significant due to steep dose gradients at the field edge. As a result, even if the geometric setup errors average out over the course of treatment, the dosimetric changes may not average out. Instead, the LAD dose may be systematically higher than seen at planning. Due to the potential importance of the dose received by the LAD, especially with studies noting cardiac perfusion defects as above, a planning organ at risk volume (PRV) with a margin of $0.5 \mathrm{~cm}$ is recommended for the LAD contour (93).

\section{ADDITIONAL HEART SPARING TECHNIQUES}

As noted above, there are now multiple techniques that can be used for cardiac sparing, including prone positioning, IMRT, and proton radiotherapy. Lateral decubitus positioning can also be utilized (94). Each of these techniques can be used in conjunction with, or as an alternative to, DIBH. In order to select the optimal technique, comparisons must be made of each treatment combination. Treatment in the prone position takes advantage of gravity in order to pull the breast away from the CW. This allows the utilization of shallow tangent beams. Dosimetric studies uniformally find that the prone position reduces lung dose from whole breast radiotherapy (22). Most dosimetric series of left breast irradiation find that heart dose is lower in the prone position as compared to supine free breathing, however, because in certain patients the heart can fall forward with gravity (95), the benefit in cardiac dose sparing with prone positioning can vary $(22,96,97)$. For this reason, coverage of the IMC can be prohibitive in the prone position due to heart dose. However, nodal radiotherapy in the prone position is feasible if the IMC is to be omitted $(98,99)$. In dosimetric comparisons of the prone position versus supine DIBH, lung dose was lower in the prone position while heart dose was lower with supine DIBH $(27,100)$. A group in Belgium has explored by combining these techniques $(28,29)$. Early data suggest that prone DIBH combines the best of these two techniques yielding very low lung dose (similar to the prone position) and very low heart dose (similar to DIBH). Whether the small incremental improvements in heart and lung dose provided by prone DIBH yield clinical advantages is not yet known.

Proton therapy is another breast cancer radiation modality used to spare heart radiation exposure, taking advantage of the dosimetric properties of protons to reduce cardiac doses. Recent series have shown remarkably low cardiac doses with 
proton therapy (101). Comparisons of protons at free-breathing versus photons with DIBH have shown that both techniques yield remarkably low heart doses, although proton plans appear to deliver lower mean heart dose and lower dose to the LAD (102). Whether the very small differences in mean heart dose between protons and photons at DIBH will be clinically relevant is in question. Combination series of protons delivered at DIBH have appeared to show no significant improvements over protons at free breathing (103). Notably, the breast contour can evolve significant during radiotherapy due to reabsorption of the seroma or breast edema of shrinkage (104). Proton dosimetry is somewhat less robust to changes in breast size that can occur over the course of treatment as compared to photon plans. As a result, imaging during the RT course and replanning in the event of a contour change, could be considered. Whether the very small differences in mean heart dose between photons using DIBH and protons, and whether the physical and biological uncertainties associated with protons, will be clinically relevant is in question. These questions may be answered by the currently accruing PCORI RADCOMP trial (105). This trial aims to enroll 1,716 patients receiving radiotherapy to the breast or $\mathrm{CW}$ in conjunction with the internal mammary nodes and randomize them to radiotherapy with either protons or photons. The primary endpoints of this trial are cardiac events and cancer control events.

There is not yet consensus in the field coalescing around an optimal technique or combination of techniques for cardiac sparing, as evidenced by ongoing investigations and the PICORI RADCOMP trial. We currently favor the use of the prone position or supine $\mathrm{DIBH}$ when treating the intact left breast. When treating the left breast or CW and regional nodes, we typically create a plan using $3 \mathrm{D}$ conformal radiation therapy with the patient supine at DIBH, and use this approach to treat the majority of patients. IMRT at

\section{REFERENCES}

1. Early Breast Cancer Trialists' Collaborative Group (EBCTCG), Darby S, McGale P, Correa C, Taylor C, Arriagada R, et al. Effect of radiotherapy after breast-conserving surgery on 10-year recurrence and 15-year breast cancer death: meta-analysis of individual patient data for 10,801 women in 17 randomised trials. Lancet (2011) 378:1707-16. doi:10.1016/ S0140-6736(11)61629-2

2. EBCTCG (Early Breast Cancer Trialists' Collaborative Group), McGale P, Taylor C, Correa C, Cutter D, Duane F, et al. Effect of radiotherapy after mastectomy and axillary surgery on 10-year recurrence and 20-year breast cancer mortality: meta-analysis of individual patient data for 8135 women in 22 randomised trials. Lancet (2014) 383:2127-35. doi:10.1016/ S0140-6736(14)60488-8

3. Early Breast Cancer Trialists' Collaborative Group. Favourable and unfavourable effects on long-term survival of radiotherapy for early breast cancer: an overview of the randomised trials. Lancet (2000) 355:1757-70. doi:10.1016/ S0140-6736(00)02263-7

4. Hooning MJ, Aleman BM, van Rosmalen AJ, Kuenen MA, Klijn JG, van Leeuwen FE. Cause-specific mortality in long-term survivors of breast cancer: a 25-year follow-up study. Int J Radiat Oncol Biol Phys (2006) 64:1081-91. doi:10.1016/j.ijrobp.2005.10.022

5. Rutqvist LE, Johansson H. Mortality by laterality of the primary tumour among 55,000 breast cancer patients from the Swedish Cancer Registry. $\mathrm{Br}$ J Cancer (1990) 61:866-8. doi:10.1038/bjc.1990.193

6. Henson KE, McGale P, Taylor C, Darby SC. Radiation-related mortality from heart disease and lung cancer more than 20 years after radiotherapy for breast cancer. Br J Cancer (2013) 108:179-82. doi:10.1038/bjc.2012.575
$\mathrm{DIBH}$ is considered in the event that normal tissue constraints are not met with a 3D conformal radiation therapy approach.

\section{CONCLUSION}

Radiation therapy for breast cancer has been proven to improve both local control and overall survival in patients; however, cardiac toxicity associated with radiation dose to the heart may partially negate these effects. Improvements and advances in radiation technology and delivery over time have led to dramatic decreases in heart doses for those receiving breast cancer radiation. DIBH is an important tool for cardiac sparing and has been reproducibly associated with a reduction of mean heart dose. This benefit is the greatest in those patients with left-sided disease and those receiving IMC irradiation. DIBH has also been shown to decrease dose to the lungs. Further studies aimed to enhance DIBH techniques and to optimize patient selection for DIBH are ongoing.

\section{AUTHOR CONTRIBUTIONS}

$\mathrm{CB}, \mathrm{AC}, \mathrm{ND}, \mathrm{AT}$, and JS conceived of the manuscript, drafted the manuscript, and approved of the final version to be published.

\section{FUNDING}

CB received support from the Institutional Research Grant 86-004-26 from the American Cancer Society, Mary Kay Foundation Grant 017-29, Susan G. Komen ${ }^{\circledR}$ Grant CCR17483233, and the National Centers for Research Resources and Advancing Translational Sciences and the Office of the Director of the NIH through Grant 8KL2TR000056. CB and AC are supported by the Nancy Laning Sobczak, Ph.D., Breast Cancer Research Award.

7. Gyenes G, Rutqvist LE, Liedberg A, Fornander T. Long-term cardiac morbidity and mortality in a randomized trial of pre- and postoperative radiation therapy versus surgery alone in primary breast cancer. Radiother Oncol (1998) 48:185-90. doi:10.1016/S0167-8140(98)00062-0

8. Taylor C, Correa C, Duane FK, Aznar MC, Anderson SJ, Bergh J, et al. Estimating the risks of breast cancer radiotherapy: evidence from modern radiation doses to the lungs and heart and from previous randomized trials. J Clin Oncol (2017) 35:1641-9. doi:10.1200/JCO.2016.72.0722

9. Darby SC, Ewertz M, McGale P, Bennet AM, Blom-Goldman U, Brønnum D, et al. Risk of ischemic heart disease in women after radiotherapy for breast cancer. N Engl J Med (2013) 368:987-98. doi:10.1056/NEJMoa1209825

10. Hooning MJ, Botma A, Aleman BM, Baaijens MH, Bartelink H, Klijn JG, et al. Long-term risk of cardiovascular disease in 10-year survivors of breast cancer. J Natl Cancer Inst (2007) 99:365-75. doi:10.1093/jnci/djk064

11. Harris EE, Correa C, Hwang WT, Liao J, Litt HI, Ferrari VA, et al. Late cardiac mortality and morbidity in early-stage breast cancer patients after breast-conservation treatment. J Clin Oncol (2006) 24:4100-6. doi:10.1200/ JCO.2005.05.1037

12. Shapiro CL, Hardenbergh PH, Gelman R, Blanks D, Hauptman P, Recht A, et al. Cardiac effects of adjuvant doxorubicin and radiation therapy in breast cancer patients. J Clin Oncol (1998) 16:3493-501. doi:10.1200/ JCO.1998.16.11.3493

13. Sardaro A, Petruzzelli MF, D’Errico MP, Grimaldi L, Pili G, Portaluri M. Radiation-induced cardiac damage in early left breast cancer patients: risk factors, biological mechanisms, radiobiology, and dosimetric constraints. Radiother Oncol (2012) 103:133-42. doi:10.1016/j.radonc.2012.02.008

14. Thorsen LB, Offersen BV, Danø H, Berg M, Jensen I, Pedersen AN, et al. DBCG-IMN: a population-based cohort study on the effect of internal 
mammary node irradiation in early node-positive breast cancer. J Clin Oncol (2016) 34:314-20. doi:10.1200/JCO.2015.63.6456

15. Hennequin C, Bossard N, Servagi-Vernat S, Maingon P, Dubois JB, Datchary J, et al. Ten-year survival results of a randomized trial of irradiation of internal mammary nodes after mastectomy. Int J Radiat Oncol Biol Phys (2013) 86:860-6. doi:10.1016/j.ijrobp.2013.03.021

16. Poortmans PM, Collette S, Kirkove C, Van Limbergen E, Budach V, Struikmans $\mathrm{H}$, et al. Internal mammary and medial supraclavicular irradiation in breast cancer. N Engl J Med (2015) 373:317-27. doi:10.1056/ NEJMoa1415369

17. Whelan TJ, Olivotto IA, Parulekar WR, Ackerman I, Chua BH, Nabid A, et al. Regional nodal irradiation in early-stage breast cancer. N Engl J Med (2015) 373:307-16. doi:10.1056/NEJMoa1415340

18. Chargari C, Castadot P, Macdermed D, Vandekerkhove C, Bourgois N, Van Houtte $\mathrm{P}$, et al. Internal mammary lymph node irradiation contributes to heart dose in breast cancer. Med Dosim (2010) 35:163-8. doi:10.1016/j. meddos.2009.05.002

19. Cuzick J, Stewart H, Rutqvist L, Houghton J, Edwards R, Redmond C, et al. Cause-specific mortality in long-term survivors of breast cancer who participated in trials of radiotherapy. J Clin Oncol (1994) 12:447-53. doi:10.1200/ JCO.1994.12.3.447

20. Bouillon K, Haddy N, Delaloge S, Garbay JR, Garsi JP, Brindel P, et al. Longterm cardiovascular mortality after radiotherapy for breast cancer. J Am Coll Cardiol (2011) 57:445-52. doi:10.1016/j.jacc.2010.08.638

21. Darby SC, McGale P, Taylor CW, Peto R. Long-term mortality from heart disease and lung cancer after radiotherapy for early breast cancer: prospective cohort study of about 300,000 women in US SEER cancer registries. Lancet Oncol (2005) 6:557-65. doi:10.1016/S1470-2045(05)70251-5

22. Formenti SC, DeWyngaert J, Jozsef G, Goldberg JD. Prone vs supine positioning for breast cancer radiotherapy. JAMA (2012) 308:861-3. doi:10.1001/2012.jama.10759

23. MacDonald SM, Jimenez R, Paetzold P, Adams J, Beatty J, DeLaney TF, et al. Proton radiotherapy for chest wall and regional lymphatic radiation; dose comparisons and treatment delivery. Radiat Oncol (2013) 8:71. doi:10.1186/1748-717X-8-71

24. Ares C, Khan S, Macartain AM, Heuberger J, Goitein G, Gruber G, et al. Postoperative proton radiotherapy for localized and locoregional breast cancer: potential for clinically relevant improvements? Int J Radiat Oncol Biol Phys (2010) 76:685-97. doi:10.1016/j.ijrobp.2009.02.062

25. Lohr F, El-Haddad M, Dobler B, Grau R, Wertz HJ, Kraus-Tiefenbacher U, et al. Potential effect of robust and simple IMRT approach for left-sided breast cancer on cardiac mortality. Int J Radiat Oncol Biol Phys (2009) 74:73-80. doi:10.1016/j.ijrobp.2008.07.018

26. Latty D, Stuart KE, Wang W, Ahern V. Review of deep inspiration breathhold techniques for the treatment of breast cancer. J Med Radiat Sci (2015) 62:74-81. doi:10.1002/jmrs. 96

27. Verhoeven K, Sweldens C, Petillion S, Laenen A, Peeters S, Janssen H, et al. Breathing adapted radiation therapy in comparison with prone position to reduce the doses to the heart, left anterior descending coronary artery, and contralateral breast in whole breast radiation therapy. Pract Radiat Oncol (2014) 4:123-9. doi:10.1016/j.prro.2013.07.005

28. Mulliez T, Veldeman L, Speleers B, Mahjoubi K, Remouchamps V, Van Greveling A, et al. Heart dose reduction by prone deep inspiration breath hold in left-sided breast irradiation. Radiother Oncol (2015) 114:79-84. doi:10.1016/j.radonc.2014.11.038

29. Mulliez T, Van de Velde J, Veldeman L, De Gersem W, Vercauteren T, Speleers B, et al. Deep inspiration breath hold in the prone position retracts the heart from the breast and internal mammary lymph node region. Radiother Oncol (2015) 117:473-6. doi:10.1016/j.radonc.2015.09.030

30. Wong JW, Sharpe MB, Jaffray DA, Kini VR, Robertson JM, Stromberg JS, et al. The use of active breathing control $(\mathrm{ABC})$ to reduce margin for breathing motion. Int J Radiat Oncol Biol Phys (1999) 44:911-9. doi:10.1016/ S0360-3016(99)00056-5

31. Remouchamps VM, Vicini FA, Sharpe MB, Kestin LL, Martinez AA, Wong JW. Significant reductions in heart and lung doses using deep inspiration breath hold with active breathing control and intensity-modulated radiation therapy for patients treated with locoregional breast irradiation. Int J Radiat Oncol Biol Phys (2003) 55:392-406. doi:10.1016/S0360-3016(02)04143-3
32. Remouchamps VM, Letts N, Vicini FA, Sharpe MB, Kestin LL, Chen PY, et al. Initial clinical experience with moderate deep-inspiration breath hold using an active breathing control device in the treatment of patients with left-sided breast cancer using external beam radiation therapy. Int $\mathrm{J}$ Radiat Oncol Biol Phys (2003) 56:704-15. doi:10.1016/S0360-3016(03)00010-5

33. Stranzl H, Zurl B. Postoperative irradiation of left-sided breast cancer patients and cardiac toxicity. Does deep inspiration breath-hold (DIBH) technique protect the heart? Strahlenther Onkol (2008) 184:354-8. doi:10.1007/ s00066-008-1852-0

34. Stranzl H, Zurl B, Langsenlehner T, Kapp KS. Wide tangential fields including the internal mammary lymph nodes in patients with left-sided breast cancer. Influence of respiratory-controlled radiotherapy (4D-CT) on cardiac exposure. Strahlenther Onkol (2009) 185:155-60. doi:10.1007/s00066-009-1939-2

35. Borst GR, Sonke JJ, den Hollander S, Betgen A, Remeijer P, van Giersbergen A, et al. Clinical results of image-guided deep inspiration breath hold breast irradiation. Int J Radiat Oncol Biol Phys (2010) 78:1345-51. doi:10.1016/j. ijrobp.2009.10.006

36. Johansen S, Vikström J, Hjelstuen MH, Mjaaland I, Dybvik KI, Olsen DR. Dose evaluation and risk estimation for secondary cancer in contralateral breast and a study of correlation between thorax shape and dose to organs at risk following tangentially breast irradiation during deep inspiration breath-hold and free breathing. Acta Oncol (2011) 50:563-8. doi:10.3109/ 0284186X.2010.541933

37. McIntosh A, Shoushtari AN, Benedict SH, Read PW, Wijesooriya K. Quantifying the reproducibility of heart position during treatment and corresponding delivered heart dose in voluntary deep inhalation breath hold for left breast cancer patients treated with external beam radiotherapy. Int J Radiat Oncol Biol Phys (2011) 81:e569-76. doi:10.1016/j.jirobp.2011.01.044

38. Vikström J, Hjelstuen MH, Mjaaland I, Dybvik KI. Cardiac and pulmonary dose reduction for tangentially irradiated breast cancer, utilizing deep inspiration breath-hold with audio-visual guidance, without compromising target coverage. Acta Oncol (2011) 50:42-50. doi:10.3109/0284186X.2010.512923

39. Hayden AJ, Rains M, Tiver K. Deep inspiration breath hold technique reduces heart dose from radiotherapy for left-sided breast cancer. J Med Imaging Radiat Oncol (2012) 56:464-72. doi:10.1111/j.1754-9485.2012.02405.x

40. Hjelstuen MHB, Mjaaland I, Vikström J, Dybvik KI. Radiation during deep inspiration allows loco-regional treatment of left breast and axillary-, supraclavicular- and internal mammary lymph nodes without compromising target coverage or dose restrictions to organs at risk. Acta Oncol (2012) 51:333-44. doi:10.3109/0284186X.2011.618510

41. Wang W, Purdie TG, Rahman M, Marshall A, Liu FF, Fyles A. Rapid automated treatment planning process to select breast cancer patients for active breathing control to achieve cardiac dose reduction. Int J Radiat Oncol Biol Phys (2012) 82:386-93. doi:10.1016/j.jirobp.2010.09.026

42. Bruzzaniti $\mathrm{V}$, Abate $\mathrm{A}$, Pinnarò $\mathrm{P}$, D’Andrea $\mathrm{M}$, Infusino $\mathrm{E}$, Landoni $\mathrm{V}$, et al. Dosimetric and clinical advantages of deep inspiration breath-hold (DIBH) during radiotherapy of breast cancer. J Exp Clin Cancer Res (2013) 32:88. doi:10.1186/1756-9966-32-88

43. Lee HY, Chang JS, Lee IJ, Park K, Kim YB, Suh CO, et al. The deep inspiration breath hold technique using Abches reduces cardiac dose in patients undergoing left-sided breast irradiation. Radiat Oncol J (2013) 31:239-46. doi:10.3857/roj.2013.31.4.239

44. Mast ME, van Kempen-Harteveld L, Heijenbrok MW, Kalidien Y, Rozema H, Jansen WP, et al. Left-sided breast cancer radiotherapy with and without breath-hold: does IMRT reduce the cardiac dose even further? Radiother Oncol (2013) 108:248-53. doi:10.1016/j.radonc.2013.07.017

45. Nissen HD, Appelt AL. Improved heart, lung and target dose with deep inspiration breath hold in a large clinical series of breast cancer patients. Radiother Oncol (2013) 106:28-32. doi:10.1016/j.radonc.2012.10.016

46. Reardon KA, Read PW, Morris MM, Reardon MA, Geesey C, Wijesooriya K. A comparative analysis of 3D conformal deep inspiratory-breath hold and free-breathing intensity-modulated radiation therapy for left-sided breast cancer. Med Dosim (2013) 38:190-5. doi:10.1016/j.meddos.2013.01.002

47. Swanson T, Grills IS, Ye H, Entwistle A, Teahan M, Letts N, et al. Six-year experience routinely using moderate deep inspiration breath-hold for the reduction of cardiac dose in left-sided breast irradiation for patients with early-stage or locally advanced breast cancer. Am J Clin Oncol (2013) 36:24-30. doi:10.1097/COC.0b013e31823fe481 
48. Bolukbasi Y, Saglam Y, Selek U, Topkan E, Kataria A, UnalZ, et al. Reproducible deep-inspiration breath-hold irradiation with forward intensity-modulated radiotherapy for left-sided breast cancer significantly reduces cardiac radiation exposure compared to inverse intensity-modulated radiotherapy. Tumori (2014) 100:169-78. doi:10.1700/1491.16405

49. Comsa D, Barnett E, Le K, Mohamoud G, Zaremski D, Fenkell L, et al. Introduction of moderate deep inspiration breath hold for radiation therapy of left breast: initial experience of a regional cancer center. Pract Radiat Oncol (2014) 4:298-305. doi:10.1016/j.prro.2013.10.006

50. Osman SO, Hol S, Poortmans PM, Essers M. Volumetric modulated arc therapy and breath-hold in image-guided locoregional left-sided breast irradiation. Radiother Oncol (2014) 112:17-22. doi:10.1016/j.radonc.2014. 04.004

51. Eldredge-Hindy H, Lockamy V, Crawford A, Nettleton V, Werner-Wasik M, Siglin J, et al. Active Breathing Coordinator reduces radiation dose to the control in patients with left breast cancer: report of a prospective heart and preserves local trial. Pract Radiat Oncol (2015) 5:4-10. doi:10.1016/j. prro.2014.06.004

52. Joo JH, Kim SS, Ahn SD, Kwak J, Jeong C, Ahn SH, et al. Cardiac dose reduction during tangential breast irradiation using deep inspiration breath hold: a dose comparison study based on deformable image registration. Radiat Oncol (2015) 10:264. doi:10.1186/s13014-015-0573-7

53. Rochet N, Drake JI, Harrington K, Wolfgang JA, Napolitano B, Sadek BT, et al. Deep inspiration breath-hold technique in left-sided breast cancer radiation therapy: evaluating cardiac contact distance as a predictor of cardiac exposure for patient selection. Pract Radiat Oncol (2015) 5:e127-34. doi:10.1016/j.prro.2014.08.003

54. Tanguturi SK, Lyatskaya Y, Chen Y, Catalano PJ, Chen MH, Yeo WP, et al. Prospective assessment of deep inspiration breath-hold using 3-dimensional surface tracking for irradiation of left-sided breast cancer. Pract Radiat Oncol (2015) 5:358-65. doi:10.1016/j.prro.2015.06.002

55. Wiant D, Wentworth S, Liu H, Sintay B. How important is a reproducible breath hold for deep inspiration breath hold breast radiation therapy? Int J Radiat Oncol Biol Phys (2015) 93:901-7. doi:10.1016/j.ijrobp.2015.06.010

56. Yeung R, Conroy L, Long K, Walrath D, Li H, Smith W, et al. Cardiac dose reduction with deep inspiration breath hold for left-sided breast cancer radiotherapy patients with and without regional nodal irradiation. Radiat Oncol (2015) 10:200. doi:10.1186/s13014-015-0511-8

57. Walston S, Quick AM, Kuhn K, Rong Y. Dosimetric considerations in respiratory-gated deep inspiration breath-hold for left breast irradiation. Technol Cancer Res Treat (2017) 16:22-32. doi:10.1177/1533034615624311

58. Lawler G, Leech M. Dose sparing potential of deep inspiration breath-hold technique for left breast cancer radiotherapy organs-at-risk. Anticancer Res (2017) 37:883-90. doi:10.21873/anticanres.11394

59. Kunheri B, Kotne S, Nair SS, Makuny D. A dosimetric analysis of cardiac dose with or without active breath coordinator moderate deep inspiratory breath hold in left sided breast cancer radiotherapy. J Cancer Res Ther (2017) 13:56-61. doi:10.4103/jcrt.JCRT_1414_16

60. Mohamad O, Shiao J, Zhao B, Roach K, Ramirez E, Vo DT, et al. Deep inspiration breathhold for left-sided breast cancer patients with unfavorable cardiac anatomy requiring internal mammary nodal irradiation. Pract Radiat Oncol (2017) 7:e361-7. doi:10.1016/j.prro.2017.04.006

61. Bartlett FR, Colgan RM, Carr K, Donovan EM, McNair HA, Locke I, et al. The UK HeartSpare Study: randomised evaluation of voluntary deep-inspiratory breath-hold in women undergoing breast radiotherapy. Radiother Oncol (2013) 108:242-7. doi:10.1016/j.radonc.2013.04.021

62. Eldredge-Hindy HB, Duffy D, Yamoah K, Simone NL, SkowronskiJ, Dicker AP, et al. Modeled risk of ischemic heart disease following left breast irradiation with deep inspiration breath hold. Pract Radiat Oncol (2015) 5:162-8. doi:10.1016/j.prro.2014.10.002

63. Macrie BD, Donnelly ED, Hayes JP, Gopalakrishnan M, Philip RT, Reczek J, et al. A cost-effective technique for cardiac sparing with deep inspiration-breath hold (DIBH). Phys Med (2015) 31:733-7. doi:10.1016/j. ejmp.2015.06.006

64. Kubo HD, Len PM, Minohara S, Mostafavi H. Breathing-synchronized radiotherapy program at the University of California Davis Cancer Center. Med Phys (2000) 27:346-53. doi:10.1118/1.598837

65. Rong Y, Walston S, Welliver MX, Chakravarti A, Quick AM. Improving intra-fractional target position accuracy using a $3 \mathrm{D}$ surface surrogate for left breast irradiation using the respiratory-gated deep-inspiration breath-hold technique. PLoS One (2014) 9:e97933. doi:10.1371/journal.pone.0097933

66. Peng JL, Kahler D, Li JG, Samant S, Yan G, Amdur R, et al. Characterization of a real-time surface image-guided stereotactic positioning system. Med Phys (2010) 37:5421-33. doi:10.1118/1.3483783

67. Alderliesten T, Sonke JJ, Betgen A, Honnef J, van Vliet-Vroegindeweij C, Remeijer P. Accuracy evaluation of a 3-dimensional surface imaging system for guidance in deep-inspiration breath-hold radiation therapy. Int J Radiat Oncol Biol Phys (2013) 85:536-42. doi:10.1016/j.ijrobp.2012.04.004

68. Betgen A, Alderliesten T, Sonke JJ, van Vliet-Vroegindeweij C, Bartelink H, Remeijer P. Assessment of set-up variability during deep inspiration breath hold radiotherapy for breast cancer patients by 3D-surface imaging. Radiother Oncol (2013) 106:225-30. doi:10.1016/j.radonc.2012.12.016

69. Tang X, Zagar TM, Bair E, Jones EL, Fried D, Zhang L, et al. Clinical experience with 3-dimensional surface matching-based deep inspiration breath hold for left-sided breast cancer radiation therapy. Pract Radiat Oncol (2014) 4:e151-8. doi:10.1016/j.prro.2013.05.004

70. RemouchampsVM,HuyskensDP,MertensI,DestineM,VanEschA,SalamonE, et al. The use of magnetic sensors to monitor moderate deep inspiration breath hold during breast irradiation with dynamic MLC compensators. Radiother Oncol (2007) 82:341-8. doi:10.1016/j.radonc.2006.11.015

71. Jensen C, Urribarri J, Cail D, Rottmann J, Mishra P, Lingos T, et al. Cine EPID evaluation of two non-commercial techniques for DIBH. Med Phys (2014) 41:21730. doi:10.1118/1.4862835

72. Visscher S, Barnett E. Comparison of bolus materials to highly absorbent polypropylene and Rayon cloth. J Med Imaging Radiat Sci (2017) 48:55-60. doi:10.1016/j.jmir.2016.08.003

73. Hong JC, Rahimy E, Gross CP, Shafman T, Hu X, Yu JB, et al. Radiation dose and cardiac risk in breast cancer treatment: an analysis of modern radiation therapy including community settings. Pract Radiat Oncol (2017). doi:10.1016/j.prro.2017.07.005

74. Gyenes G, Fornander T, Carlens P, Glas U, Rutqvist LE. Detection of radiation-induced myocardial damage by technetium-99m sestamibi scintigraphy. Eur J Nucl Med (1997) 24:286-92. doi:10.1007/BF01728765

75. Evans ES, Prosnitz RG, Yu X, Zhou SM, Hollis DR, Wong TZ, et al. Impact of patient-specific factors, irradiated left ventricular volume, and treatment set-up errors on the development of myocardial perfusion defects after radiation therapy for left-sided breast cancer. Int J Radiat Oncol Biol Phys (2006) 66:1125-34. doi:10.1016/j.ijrobp.2006.06.025

76. Chung E, Corbett JR, Moran JM, Griffith KA, Marsh RB, Feng M, et al. Is there a dose-response relationship for heart disease with low-dose radiation therapy? Int J Radiat Oncol Biol Phys (2013) 85:959-64. doi:10.1016/j. ijrobp.2012.08.002

77. Zagar TM, Kaidar-Person O, Tang X, Jones EE, Matney J, Das SK, et al. Utility of deep inspiration breath hold for left-sided breast radiation therapy in preventing early cardiac perfusion defects: a prospective study. Int J Radiat Oncol Biol Phys (2017) 97:903-9. doi:10.1016/j.ijrobp.2016.12.017

78. Zellars R, Bravo PE, Tryggestad E, Hopfer K, Myers L, Tahari A, et al. SPECT analysis of cardiac perfusion changes after whole-breast/chest wall radiation therapy with or without active breathing coordinator: results of a randomized phase 3 trial. Int J Radiat Oncol Biol Phys (2014) 88:778-85. doi:10.1016/j. ijrobp.2013.12.035

79. Smyth LM, Knight KA, Aarons YK, Wasiak J. The cardiac dose-sparing benefits of deep inspiration breath-hold in left breast irradiation: a systematic review. J Med Radiat Sci (2015) 62:66-73. doi:10.1002/jmrs.89

80. Conway JL, Conroy L, Harper L, Scheifele M, Li H, Smith WL, et al. Deep inspiration breath-hold produces a clinically meaningful reduction in ipsilateral lung dose during locoregional radiation therapy for some women with right-sided breast cancer. Pract Radiat Oncol (2017) 7:147-53. doi:10.1016/j. prro.2016.10.011

81. Taylor CW, McGale P, Povall JM, Thomas E, Kumar S, Dodwell D, et al. Estimating cardiac exposure from breast cancer radiotherapy in clinical practice. Int J Radiat Oncol Biol Phys (2009) 73:1061-8. doi:10.1016/j. ijrobp.2008.05.066

82. Kong FM, Klein EE, Bradley JD, Mansur DB, Taylor ME, Perez CA, et al. The impact of central lung distance, maximal heart distance, and radiation technique on the volumetric dose of the lung and heart for intact breast radiation. Int J Radiat Oncol Biol Phys (2002) 54:963-71. doi:10.1016/ S0360-3016(02)03741-0 
83. Lee G, Rosewall T, Fyles A, Harnett N, Dinniwell RE. Anatomic features of interest in women at risk of cardiac exposure from whole breast radiotherapy. Radiother Oncol (2015) 115:355-60. doi:10.1016/j.radonc.2015. 05.002

84. Pierce LJ, Butler JB, Martel MK, Normolle DP, Koelling T, Marsh RB, et al. Postmastectomy radiotherapy of the chest wall: dosimetric comparison of common techniques. Int J Radiat Oncol Biol Phys (2002) 52:1220-30. doi:10.1016/S0360-3016(01)02760-2

85. Thomsen MS, Berg M, Nielsen HM, Pedersen AN, Overgaard M, Ewertz M, et al. Post-mastectomy radiotherapy in Denmark: from 2D to 3D treatment planning guidelines of The Danish Breast Cancer Cooperative Group. Acta Oncol (2008) 47:654-61. doi:10.1080/02841860801975000

86. Arthur DW, Arnfield MR, Warwicke LA, Morris MM, Zwicker RD. Internal mammary node coverage: an investigation of presently accepted techniques. Int J Radiat Oncol Biol Phys (2000) 48:139-46. doi:10.1016/ S0360-3016(00)00633-7

87. Severin D, Connors S, Thompson H, Rathee S, Stavrev P, Hanson J. Breast radiotherapy with inclusion of internal mammary nodes: a comparison of techniques with three-dimensional planning. Int J Radiat Oncol Biol Phys (2003) 55:633-44. doi:10.1016/S0360-3016(02)04163-9

88. Borm KJ, Oechsner M, Combs SE, Duma MN. Deep-inspiration breathhold radiation therapy in breast cancer: a word of caution on the dose to the axillary lymph node levels. Int J Radiat Oncol Biol Phys (2018) 100:263-9. doi:10.1016/j.ijrobp.2017.09.026

89. Giuliano AE, Ballman KV, McCall L, Beitsch PD, Brennan MB, Kelemen PR, et al. Effect of axillary dissection vs no axillary dissection on 10-year overall survival among women with invasive breast cancer and sentinel node metastasis: the ACOSOG Z0011 (Alliance) randomized clinical trial. JAMA (2017) 318:918-26. doi:10.1001/jama.2017.11470

90. Jagsi R, Chadha M, Moni J, Ballman K, Laurie F, Buchholz TA, et al. Radiation field design in the ACOSOG Z0011 (Alliance) trial. J Clin Oncol (2014) 32:3600-6. doi:10.1200/JCO.2014.56.5838

91. Gierga DP, Turcotte JC, Sharp GC, Sedlacek DE, Cotter CR, Taghian AG. A voluntary breath-hold treatment technique for the left breast with unfavorable cardiac anatomy using surface imaging. Int J Radiat Oncol Biol Phys (2012) 84:e663-8. doi:10.1016/j.ijrobp.2012.07.2379

92. Jagsi R, Moran JM, Kessler ML, Marsh RB, Balter JM, Pierce LJ. Respiratory motion of the heart and positional reproducibility under active breathing control. Int JRadiat Oncol Biol Phys (2007) 68:253-8. doi:10.1016/j. ijrobp.2006.12.058

93. Wang X, Pan T, Pinnix C, Zhang SX, Salehpour M, Sun TL, et al. Cardiac motion during deep-inspiration breath-hold: implications for breast cancer radiotherapy. Int J Radiat Oncol Biol Phys (2012) 82:708-14. doi:10.1016/j. ijrobp.2011.01.035

94. Campana F, Kirova YM, Rosenwald JC, Dendale R, Vilcoq JR, Dreyfus H, et al. Breast radiotherapy in the lateral decubitus position: a technique to prevent lung and heart irradiation. Int J Radiat Oncol Biol Phys (2005) 61:1348-54. doi:10.1016/j.ijrobp.2004.08.051

95. Chino JP, Marks LB. Prone positioning causes the heart to be displaced anteriorly within the thorax: implications for breast cancer treatment. Int J Radiat Oncol Biol Phys (2008) 70:916-20. doi:10.1016/j.ijrobp.2007.11.001

96. Lymberis SC, deWyngaert JK, Parhar P, Chhabra AM, FentonKerimian M, Chang J, et al. Prospective assessment of optimal individual position (prone versus supine) for breast radiotherapy: volumetric and dosimetric correlations in 100 patients. Int J Radiat Oncol Biol Phys (2012) 84:902-9. doi:10.1016/j.ijrobp.2012.01.040

97. Griem KL, Fetherston P, Kuznetsova M, Foster GS, Shott S, Chu J. Threedimensional photon dosimetry: a comparison of treatment of the intact breast in the supine and prone position. Int J Radiat Oncol Biol Phys (2003) 57:891-9. doi:10.1016/S0360-3016(03)00723-5

98. Gielda BT, Strauss JB, Marsh JC, Turian JV, Griem KL. A dosimetric comparison between the supine and prone positions for three-field intact breast radiotherapy. Am J Clin Oncol (2011) 34:223-30. doi:10.1097/ COC.0b013e3181dbb9c1

99. Deseyne P, Speleers B, De Neve W, Boute B, Paelinck L, Van Hoof T, et al. Whole breast and regional nodal irradiation in prone versus supine position in left sided breast cancer. Radiat Oncol (2017) 12:89. doi:10.1186/ s13014-017-0828-6

100. Bartlett FR, Colgan RM, Donovan EM, McNair HA, Carr K, Evans PM, et al. The UK HeartSpare Study (Stage IB): randomised comparison of a voluntary breath-hold technique and prone radiotherapy after breast conserving surgery. Radiother Oncol (2015) 114:66-72. doi:10.1016/j.radonc.2014. 11.018

101. Bradley JA, Dagan R, Ho MW, Rutenberg M, Morris CG, Li Z, et al. Initial report of a prospective dosimetric and clinical feasibility trial demonstrates the potential of protons to increase the therapeutic ratio in breast cancer compared with photons. Int J Radiat Oncol Biol Phys (2016) 95:411-21 doi:10.1016/j.ijrobp.2015.09.018

102. Lin LL, Vennarini S, Dimofte A, Ravanelli D, Shillington K, Batra S, et al. Proton beam versus photon beam dose to the heart and left anterior descending artery for left-sided breast cancer. Acta Oncol (2015) 54:1032-9. doi:10.3 109/0284186X.2015.1011756

103. Patel SA, Lu HM, Nyamwanda JA, Jimenez RB, Taghian AG, MacDonald SM, et al. Postmastectomy radiation therapy technique and cardiopulmonary sparing: a dosimetric comparative analysis between photons and protons with free breathing versus deep inspiration breath hold. Pract Radiat Oncol (2017) 7:e377-84. doi:10.1016/j.prro.2017.06.006

104. Jacobson G, Betts V, Smith B. Change in volume of lumpectomy cavity during external beam irradiation of the intact breast. Int J Radiat Oncol Biol Phys (2006) 65(4):1161-4. doi:10.1016/j.ijrobp.2006.02.009

105. MacDonald SM. Proton therapy for breast cancer: getting to the heart of the matter. Int J Radiat Oncol Biol Phys (2016) 95:46-8. doi:10.1016/j. ijrobp.2015.11.035

Conflict of Interest Statement: The authors declare that the research was conducted in the absence of any commercial or financial relationships that could be construed as a potential conflict of interest.

Copyright (c) 2018 Bergom, Currey, Desai, Tai and Strauss. This is an open-access article distributed under the terms of the Creative Commons Attribution License (CC $B Y)$. The use, distribution or reproduction in other forums is permitted, provided the original author(s) and the copyright owner are credited and that the original publication in this journal is cited, in accordance with accepted academic practice. No use, distribution or reproduction is permitted which does not comply with these terms. 